\title{
Increased Left Ventricular Diastolic Stiffness Is Associated With Heart Failure Symptoms in Aortic Stenosis Patients With Preserved Ejection Fraction
}

\author{
DAISUKE KAMIMURA, MD, PhD, TAKEKI SUZUKI, MD, MPH, PhD, ERVIN R. FOX, MD, MPH, \\ THOMAS N. SKELTON, MD, MICHAEL D. WINNIFORD, MD, and MICHAEL E. HALL, MD, MS \\ Department of Medicine, University of Mississippi Medical Center, Jackson, Mississippi
}

\begin{abstract}
Background-Clinical risk factors associated with heart failure (HF) symptoms in aortic stenosis (AS) patients with preserved ejection fraction (EF) have not been fully identified. We hypothesized that left ventricular (LV) diastolic stiffness is associated with HF symptoms in patients with AS.
\end{abstract}

Methods and Results-We retrospectively evaluated 275 patients with at least moderate AS (aortic valve area $<1.5 \mathrm{~cm}^{2}$ ) and preserved EF ( $250 \%$ ). LV diastolic stiffness was evaluated with the use of echocardiographic parameters, diastolic wall strain (DWS, a measure of LV wall stiffness), and $\mathrm{K}_{\mathrm{LV}}$ (a marker of LV chamber stiffness). There were 69 patients with HF. Patients with HF were older, were more likely to be African American, had a higher body mass index, and had more hypertension and coronary artery disease $(P<.05$ for all). Aortic valve area index and mean pressure gradient across the aortic valve were not different between patients with and without HF. Despite similar echocardiographic parameters of AS severity, patients with HF had stiffer $\mathrm{LV}$ (DWS $0.21 \pm 0.06$ vs $0.25 \pm 0.06[P<.01], \mathrm{K}_{\mathrm{LV}} 0.17 \pm 0.11$ vs $0.13 \pm 0.08[P<.01]$ ). Logistic regression analyses revealed that after adjusting for age, race, body mass index, history of hypertension, and coronary artery disease, LV diastolic stiffness parameters remained significantly associated with HF symptoms.

Conclusions-LV diastolic stiffness is independently associated with HF in AS patients with preserved EF.

\section{Keywords}

Aortic valve stenosis; diastolic stiffness; echocardiography

\begin{abstract}
With aging of the population in developed countries, aortic stenosis (AS) is becoming an increasingly important global public health issue. It is estimated that $>12 \%$ of individuals in Europe and North America $>75$ years of age have more than mild AS. ${ }^{1}$ AS patients who develop heart failure (HF) symptoms have a very poor prognosis without treatment. ${ }^{2}$ Patients
\end{abstract}

Reprint requests: Daisuke Kamimura, MD, PhD, Department of Medicine-Cardiology, University of Mississippi Medical Center, 2500 North State Street, Jackson, Mississippi 39216. Tel: +1 601984 4607; Fax: +1 601984 5608. dkamimura@ umc.edu.

Disclosures

None. 
with severe AS often develop HF symptoms even when left ventricular (LV) systolic function is preserved. ${ }^{3}$ Although this has been largely attributed to the development of diastolic dysfunction, the specific effect of AS on LV diastolic stiffness, a major determinant of diastolic function, remains uncertain.

In asymptomatic patients with hypertension or diabetes who have compensated LV hypertrophy, increased LV diastolic stiffness plays a critical role in the development of HF with preserved ejection fraction (HFpEF) ${ }^{4,5}$ Whether LV diastolic stiffness also plays a crucial role in the development of HF symptoms in AS patients with preserved ejection fraction (EF) has not been well clarified. Diastolic wall strain (DWS) is a recently developed indicator of LV diastolic myocardial stiffness that can be calculated easily from routinely obtained echocardiographic indices. ${ }^{6} \mathrm{~K}_{\mathrm{LV}}$ is another noninvasive indicator of $\mathrm{LV}$ diastolic chamber stiffness. ${ }^{7}$ The main purpose of the present study was to use these recently developed noninvasive parameters to investigate the role that LV diastolic stiffness plays in the development of HF in AS patients with preserved EF.

\section{Methods}

\section{Study Subjects}

Data were retrospectively evaluated from patients who underwent echocardiography from January 1, 2012, to December 31, 2014, at the University of Mississippi Medical Center (UMMC), Jackson, Mississippi. The study protocol was approved by the Institutional Review Board of UMMC. Patients who had an aortic valve area (AVA) $<1.5 \mathrm{~cm}^{2}$ according to the Continuity equation method were recruited. ${ }^{8}$ Among the 658 patients with echocardiograms and AVA $<1.5 \mathrm{~cm}^{2}$, a total of 373 with the following findings were excluded from the study: for patients who underwent serial echocardiograms, only the first echocardiogram during the specified time frame was included and subsequent echocardiograms were excluded ( $n=163)$, left bundle brunch block including pacing of the right ventricle $(n=42)$, insufficient echocardiographic image quality $(n=40)$, lack of relevant patient clinical data $(n=26)$, complete atrial ventricular block $(n=3)$, sick sinus syndrome $(\mathrm{n}=2), \mathrm{LV}$ outflow tract (LVOT) obstruction $(\mathrm{n}=1)$, atrial septal defect $(\mathrm{n}=1)$, cardiac tamponade $(n=1)$, septic shock $(n=1)$, reduced LVEF $(<50 \%)$, and presence of LV regional wall motion abnormality $(n=93)$. The remaining 285 AS patients were included in the study.

\section{Heart Failure Definition}

HF diagnosis was obtained from each patient's medical record. Among the 285 eligible patients identified, 79 patients were recoded as having HF symptoms, and the remaining 206 patients were without HF symptoms. In 10 of the 79 patients with HF symptoms, 6 were recovered EF and 4 were unknown previous EF; we excluded those patients. In the remaining 69 patients with HF symptoms, HF diagnosis was adjudicated with the use of the Framingham criteria by a cardiologist. ${ }^{9}$ Thirty-nine of the 69 patients with HF had an acute decompensated HFpEF event, and the remaining $30 \mathrm{HF}$ patients had chronic HFpEF at the time of echocardiography. N-Terminal pro-B-type natriuretic peptide (NT-proBNP) level 
was available in 38 of the $69 \mathrm{HFpEF}$ patients at the time of echocardiography, and the mean value of the NT-proBNP levels was $9399 \pm 1486$ (standard error) $\mathrm{pg} / \mathrm{mL}$.

\section{Medical History}

The presence of hypertension (HTN), diabetes mellitus (DM), dyslipidemia (DL), or coronary artery disease (CAD) was identified from medical record review. HTN, DM, and DL were defined as medication use for the disease or a reported history of the disease. CAD was defined as a history of percutaneous coronary intervention, coronary artery bypass graft, or a reported history of $\mathrm{CAD}$ including angina pectoris or myocardial infarction. Body mass index was defined as body weight (in $\mathrm{kg}$ )/[height (in $\mathrm{m}$ ) $]^{2}$.

\section{Echocardiography}

Echocardiography was performed with the use of an X5-1 probe mounted on an iE33 ultrasound system (Philips Medical Systems, Andover, Massachusetts). LVOT and transaortic valve blood flow velocities and gradients were derived from velocity time integrals, measured by pulsed-wave and continuous-wave Doppler, respectively, in different (including apical 5-chamber, right parasternal, and suprasternal notch) views. The Ped-off (nonimaging) probe was also used to further assess transaortic valve flow on continuous-wave Doppler. The highest and clearest profile of the transaortic time-velocity integral on spectral Doppler was selected from several views and traced, and subsequent measurements were obtained. LVOT diameter was measured at mid-systole in the 2-dimensional (2D) parasternal long-axis view by an inner-edge-to-inner-edge method. ${ }^{8,10}$ The AVA was calculated with the use of the Continuity equation. LV end-diastolic dimension (LVDd), LV end-systolic dimension (LVDs), LV posterior wall thickness at end-diastole (PWd), LV posterior wall thickness at end-systole (PWs), and LV interventricular septal wall thickness at end-diastole (IVSd) were measured in the 2D parasternal long-axis view. LV end-diastolic volume (LVEDV), LV end-systolic volume (LVESV), LVEF, and stroke volume (SV) were calculated by means of the Teichholz method, and SV was indexed to body surface area (SVI). LVEF can overestimate LV systolic function in patients with LV hypertrophy; therefore, we also measured myocardial contraction fraction (MCF), which can differentiate myocardial performance in patients with similar degrees of hypertrophy. ${ }^{11} \mathrm{MCF}$ is defined as the following equation; $\mathrm{MCF}=\mathrm{SV} /(\mathrm{LV}$ mass/1.05). Relative wall thickness (RWT) was calculated with the formula: RWT $=(2 \times \mathrm{PWd}) / \mathrm{LVDd}$. LV mass $(\mathrm{LVM})$ was calculated using the following equation as recommended by theAmerican Society of Echocardiography and indexed by body surface area: LVMI $\left(\mathrm{g} / \mathrm{m}^{2}\right)=\left(0.8 \times\left\{1.04 \times\left[(\mathrm{LVDd}+\mathrm{IVSd}+\mathrm{PWd})^{3}-\right.\right.\right.$ $\left.\left.\left.(\operatorname{LVDd})^{3}\right]\right\}+0.6\right) /$ body surface area (BSA). ${ }^{10}$ Tissue Doppler velocities of the medial mitral annulus were obtained on apical 4-chamber view to measure early diastolic myocardial velocities $\left(\mathrm{e}^{\prime}\right)$ as previously described. ${ }^{12} \mathrm{LV}$ filling pressure was estimated by calculating the ratio of $\mathrm{E}$ (peak early transmitral flow velocity) to $\mathrm{e}^{\prime} .{ }^{13} \mathrm{LV}$ diastolic myocardial and chamber stiffness were evaluated with the use of the following indicators. Diastolic wall strain $($ DWS $=[\mathrm{PWs}-\mathrm{PWd}] / \mathrm{PWs})$ theoretically reflects LV myocardial stiffness, according to the linear elastic theory. ${ }^{6} \mathrm{An}$ increase in LV myocardial stiffness results in a decrease in DWS. $\mathrm{K}_{\mathrm{LV}}\left(\mathrm{K}_{\mathrm{LV}}=[70 /(\text { Deceleration time of early trans-mitral inflow }-20 \mathrm{~ms})]^{2}\right)$ reflects LV diastolic chamber stiffness. ${ }^{7}$ Systemic arterial compliance (SAC) was evaluated indirectly as the ratio of SVI to brachial pulse pressure. ${ }^{14}$ As a measure of global LV 
afterload, the valvulo-arterial impedance (Zva) was calculated with the use of the following equation: ${ }^{14} \mathrm{Zva}=$ (systolic blood pressure + mean pressure gradient)/SVI. The energy loss index (ELI) was determined with the use of the following formula: ${ }^{15} \mathrm{ELI}=(\mathrm{AVA} \times \mathrm{Aa} /[\mathrm{Aa}$ - AVA])/BSA, where Aa is the aortic cross sectional area at the sinotubular junction.

\section{Reproducibility Analysis}

Reproducibility of the PWs, PWd, and DWS measurements were assessed in 20 of the study subjects. Two independent observers analyzed the same $2 \mathrm{D}$ echocardiographic images and 1 blinded observer repeated the analysis on a separate day. The mean and SD of the absolute differences between 2 measurements by 1 observer and between observers were, respectively, $0.97 \pm 0.70 \mathrm{~mm}$ and $1.65 \pm 0.91 \mathrm{~mm}$ for PWs, $1.06 \pm 0.85 \mathrm{~mm}$ and $1.02 \pm 0.95$ $\mathrm{mm}$ for $\mathrm{PWd}$, and $0.040 \pm 0.026$ and $0.049 \pm 0.039$ for DWS.

\section{Classification of the Severity of Aortic Stenosis}

Based on the American Society of Echocardiography guidelines, we classified AS severity into the following groups: ${ }^{8}$

1. High-gradient (HG) severe AS: AVA $<1 \mathrm{~cm}^{2}$, mean PG $\geq 40 \mathrm{~mm} \mathrm{Hg}$.

2. Low-gradient (LG) severe AS: AVA $<1 \mathrm{~cm}^{2}$, mean $\mathrm{PG}<40 \mathrm{~mm} \mathrm{Hg}$.

3. Moderate (Mod) AS: AVA $\geq 1 \mathrm{~cm}^{2}$, mean PG $<40 \mathrm{~mm} \mathrm{Hg}$.

\section{Statistical Analysis}

Results are expressed as mean \pm SD or percentage unless otherwise specified. Differences between the 2 groups were evaluated with the use of unpaired Student $t$ tests. Categoric variables were compared by means of $\chi^{2}$ tests. The cumulative frequency distributions of DWS and $\mathrm{K}_{\mathrm{LV}}$ were constructed to evaluate the distribution of the LV diastolic stiffness of AS patients. AS patients were classified and appointed a category of AS severity.

Comparison between DWS in patients with and without HF was determined for each category of AS severity. To determine clinical factors associated with HF symptoms, logistic regression analysis was performed. In mul-tivariable analyses, variables with a univariate value of $P<.05$ were incorporated into the models. Model 1 adjusted for age, body mass index, African-American race, and history of HTN and CAD. Model 2 used model 1 plus LVMI, model 3 used model 1 plus LVEF, model 4 used model 1 plus MCF, model 5 used model 1 plus E/e', and model 6 used model 1 plus SAC. Because of the limited number of patients with HF, to avoid overfitting models, we used model 1 as a baseline analysis and added other variables that were associated with HF symptoms individually to model 1. All statistical analyses were performed with the use of Stata version 14 (Stata Corp, College Station, Texas).

\section{Results}

\section{Baseline Characteristics}

The baseline characteristics of the study subjects are presented in Table 1. Patients with HF were older ( $75 \pm 13$ vs $70 \pm 13$ years of age; $P<.05$ ), were more likely to be African 
American (49\% vs 33\%; $P<.05)$, had a higher body mass index (32 \pm 9 vs $30 \pm 7 \mathrm{~kg} / \mathrm{m}^{2} ; P$ $<.05)$, and had higher prevalences of HTN $(96 \%$ vs $83 \% ; P<.01)$ and CAD $(42 \%$ vs $26 \% ; P$ $<.05)$.

\section{Echocardiographic and Hemodynamic Findings}

The echocardiographic and hemodynamic findings of the study subjects are presented in Table 2. Patients with HF had larger LVMI $\left(131 \pm 41 \mathrm{~g} / \mathrm{m}^{2}\right.$ vs $\left.112 \pm 32 \mathrm{~g} / \mathrm{m}^{2} ; P<.001\right)$. $\operatorname{LVEF}(61 \pm 7 \%$ vs $64 \pm 8 \% ; P<.01)$ and MCF $(34 \pm 9 \%$ vs $39 \pm 11 \% ; P<.001)$ were lower in patients with HF. E-wave velocity (117 \pm 28 vs $97 \pm 26 \mathrm{~cm} / \mathrm{s} ; P<.001)$, E/A ratio (1.2 \pm 0 . vs $1.0 \pm 0.46 ; P<.01), \mathrm{E} / \mathrm{e}^{\prime}$ ratio $(23 \pm 10$ vs $17 \pm 7 ; P<.001)$, LA volume index (37 \pm 14 vs $\left.31 \pm 14 \mathrm{~mL} / \mathrm{m}^{2} ; P<.01\right)$, and estimated right ventricular systolic pressure $(46 \pm 12$ vs $38 \pm 12 \mathrm{~mm} \mathrm{Hg} ; P<.001$ ) were higher in the patients with HF than in the patients without HF. SAC $\left(0.5 \pm 0.2\right.$ vs $\left.0.6 \pm 0.2 \mathrm{~mL} \mathrm{~mm} \mathrm{Hg}^{-1} \mathrm{~m}^{-2} ; P<.05\right)$ was lower in the patients with HF symptoms. Standard indicators of AS severity, including peak and mean PG, AVA, AVAI, and DLI, were not different between the 2 groups.

\section{Diastolic Stiffness Parameters}

DWS was $16 \%$ lower $(0.21 \pm 0.06$ vs $0.25 \pm 0.06 ; P<.001)$ and $\mathrm{K}_{\mathrm{LV}}$ was $31 \%$ higher $(0.17$ \pm 0.11 vs $0.13 \pm 0.08 ; P<.01$ ) in the patients with HF than in the patients without HF (Table 2). When we compared DWS in each category of AS severity, DWS was still significantly lower in the patients with HF than in the patients without HF in HG AS and Mod AS (Fig. 1). In LG AS, DWS tended to be lower in the patients with HF than patients without HF, but not statistically significantly (Fig. 1).

\section{Diastolic Stiffness and HF Symptoms}

Logistic regression analysis was conducted to examine the associations between clinical variables and HF symptoms. The results of the univariate analyses are presented in Table 3. Age, African-American race, body mass index, history of HTN and CAD, LVMI, LVEF, $\mathrm{MCF}, \mathrm{E} / \mathrm{e}^{\prime}$, DWS, $\mathrm{K}_{\mathrm{LV}}$, and SAC were significantly associated with HF symptoms. After adjustment for age, race, body mass index, and history of HTN and CAD, DWS and $\mathrm{K}_{\mathrm{LV}}$ were significantly associated with HF symptoms (Tables 4 and 5). Furthermore, even after adding LVMI (model 2), LVEF (model 3), MCF (model 4), E/e' (model 5), and SAC (model 6), DWS and $\mathrm{K}_{\mathrm{LV}}$ remained significantly associated with HF symptoms (Tables 4 and 5).

\section{Discussion}

The major finding of our study was that increased LV myocardial (DWS) and chamber $\left(\mathrm{K}_{\mathrm{LV}}\right)$ stiffness were associated with HF symptoms in AS patients with preserved EF. This finding was also found in each AS severity category. After adjustment for covariates, LV diastolic stiffness indices were still significantly associated with HF symptoms. These findings suggest that LV diastolic stiffness plays an important role in the development of HF symptoms in AS patients with preserved $\mathrm{EF}$ and that DWS and $\mathrm{K}_{\mathrm{LV}}$ may be useful new parameters that can be used to risk-stratify patients with AS. 
It has not been well clarified which risk factors are associated with HF symptoms in AS patients with preserved EF. Previous studies have examined the relationship between diastolic function and symptom status in patients with severe AS with preserved EF. ${ }^{16,17}$ Dahl et al reported that impaired LV diastolic function was associated withAS symptomatic status, mainly including dyspnea symptoms, in severe AS defined as AVA $<1.0 \mathrm{~cm}^{2}$ and preserved EF. ${ }^{16}$ In their study, symptomatic patients more often presented with grade 2 or 3 diastolic dysfunction as assessed by LV filling parameters, supporting the concept that increased diastolic stiffness plays a role in causing HF symptoms in patients with preserved LVEF. Park et al examined the relationship between symptom status and E/ $\mathrm{e}^{\prime}$ ratio, an indicator of LV filling pressure that is indirectly associated with LV stiffness, in patients with severe AS and preserved EF. ${ }^{17}$ Patients with dyspnea had higher E/ $\mathrm{e}^{\prime}$ ratios compared with asymptomatic patients, which is consistent with our results. Taken together, these findings suggest that LV hypertrophy and subsequent diastolic dysfunction and high LV filling pressures are important drivers of HF symptoms in patients with AS. However, the relationship between LV hypertrophy and diastolic filling is complex, and both early active relaxation and passive filling of the LV play important roles in the development of HF in AS. 18 Our study incrementally builds upon the findings by Dahl et al and Park et al, demonstrating that noninvasive echocardiographic markers of LV myocardial and chamber stiffness are significantly associated with HF symptoms, even after accounting for LV hypertrophy and LV filling pressures.

DWS is a recently developed indicator of LV diastolic myocardial stiffness that can be measured easily by echocardiography. DWS has been developed based on the linear elastic theory. The idea of this indicator came from the observation that if the LV myocardium is stiff, applied force on the endocardium at end-diastole can not be absorbed by the myocardium; thus, the epicardial movement is greater than in those with "softer" LV myocardium. A detailed theoretic description about the biophysical components of DWS is provided in the supplemental material. DWS has been associated with the myocardial stiffness constant in nonhuman animal models, and DWS was significantly lower in HFpEF patients than in hypertensive patients without HF and normal control subjects. ${ }^{6}$ In the present study, DWS was lower in patients with HF than in those without HF, indicating increased LV myocardial stiffness.

$\mathrm{K}_{\mathrm{LV}}$ is an indicator that reflects $\mathrm{LV}$ diastolic chamber stiffness. ${ }^{7} \mathrm{~K}_{\mathrm{LV}}$ has been developed based on Newton's second law. Deceleration time of early transmitral inflow is determined by both LV and LA stiffness, density of blood, mitral valve area, and effective length of blood inflow. LA pressure is almost constant and very low during the early diastolic period and the density of blood is constant; therefore, the deceleration time of early transmitral inflow is heavily influenced by LV stiffness. A detailed theoretic description of $\mathrm{K}_{\mathrm{LV}}$ also is provided in the supplemental material. $\mathrm{K}_{\mathrm{LV}}$ estimated from the deceleration time of early transmitral inflow has been well correlated with invasively evaluated LV stiffness in nonhuman animal experiments. ${ }^{19}$ In the present study, $\mathrm{K}_{\mathrm{LV}}$ was higher in patients with $\mathrm{HF}$ than in patients without HF, indicating increased LV chamber stiffness in patients with HF symptoms. These results demonstrate that increased LV diastolic stiffness is associated with HF symptoms in AS patients with preserved EF. It has been reported that diastolic stiffness plays a critical role in the development of HFpEF in patients with $\mathrm{HTN}^{4}$ or DM. ${ }^{5}$ The results 
of the present study suggest the significant role of LV diastolic stiffness in the development of HFpEF in AS patients as well.

Monrad et al reported that some patients with preserved EF who underwent aortic valve replacement (AVR) 10 years earlier still had abnormal exercise hemodynamics, which was attributed to increased LV muscle stiffness that would have occurred before the AVR. ${ }^{20}$ Gjertsson et al reported that in patients with AS who underwent AVR, moderate to severe diastolic dysfunction was an independent predictor of late mortality after AVR. ${ }^{21}$ These results suggest that LV myocardial stiffness was increased and affected LV hemodynamics even long after the AVR. This also suggests the importance of serial assessment of LV myocardial stiffness before and after the operation and suggests the importance of noninvasive assessment of LV myocardial stiffness.

Impaired LV systolic function is an important contributor to symptoms in HFpEF. Recently, LV global longitudinal strain was associated with outcomes in severe AS patients with preserved EF who underwent AVR. ${ }^{22}$ On the other hand, in symptomatic severe AS patients with preserved EF, global longitudinal strain and strain rate were lower than in asymptomatic severe or moderate AS patients with preserved $\mathrm{EF}^{23}$ In the present study, even after adjusting for MCF, which is highly correlated with LV strain, DWS and $\mathrm{K}_{\mathrm{LV}}$ were associated with HF symptoms. Therefore, these results suggest that the association between LV myocardial or chamber stiffness with HF symptoms is independent from the impairment of LV systolic function.

Systemic arterial stiffness has also been reported to be associated with AS symptoms. ${ }^{24-26}$ SAC reflects mainly aortic compliance, and it has been reported that reduced SAC contributes independently to increased LV afterload and decreased LV function in AS patients. ${ }^{24} \mathrm{SAC}$ has also been associated with the severity of HF symptoms in moderate to severe AS. ${ }^{25} \mathrm{Zva}$ can estimate global LV hemodynamic load as the sum of valvular and arterial loads. It has been recently reported that Zva was associated with syncope in AS patients with preserved $\mathrm{EF}^{26} \mathrm{ELI}$ is an adjusted indicator of AVA by pressure recovery, and it has been reported that reduced ELI was associated with a poor prognosis in asymptomatic AS patients. ${ }^{27}$ Because these parameters have been associated with AS symptoms, we examined the relationship between these parameters and HF symptoms. Only SAC was associated with HF symptoms in univariate analysis. Even after adjustment for SAC, diastolic stiffness indicators were still independently associated with HF symptoms. Thus, the associations between diastolic stiffness parameters and HF symptoms were independent from systemic arterial stiffness.

The prevalence of beta-blocker use and diuretics use were different between patients with and without HF, so we examined the influences of these 2 drugs on the relationships of DWS or $\mathrm{K}_{\mathrm{LV}}$ with $\mathrm{HF}$ symptoms. Even after additional adjustment for the use of these drugs, DWS and $\mathrm{K}_{\mathrm{LV}}$ were still significantly associated with HF symptoms (data not presented). Therefore, we think that the relationships of DWS or $\mathrm{K}_{\mathrm{LV}}$ with HF symptoms are independent from beta-blocker or diuretic use. 


\section{Study Strengths and Limitations}

The present study has several strengths. First, we used recently developed indicators of LV diastolic stiffness rather than measures of diastolic filling. Conventional methods of assessing LV filling, including E/A or E/e' ${ }^{\prime}$, can be affected by loading conditions. ${ }^{6}$ However, DWS and $\mathrm{K}_{\mathrm{LV}}$ are less affected by loading conditions. ${ }^{6,7}$ Second, uniformly performed echocardiography in a single institution enabled consistent reproducible measurements of echocardiographic parameters.

This study has a few limitations. First, the findings should be considered to be preliminary, based in part on an increased probability of type I error due to the large number of models tested and comparisons made in this exploratory analysis. There were only $69 \mathrm{HF}$ cases, and we could not include additional potential confounding factors. Therefore, the findings should be confirmed in a larger sample size in a future study. Second, about one-half of the patients had moderate AS. CAD was more common in the moderate AS patients with than without HF ( $41 \%$ vs $25 \% ; P=.058$ ), raising the possibility that HF symptoms in this group may have been due to CAD rather than AS. However, the prevalence of CAD was $\sim 42 \%$ in HF patients and the mean value of LVEF in both groups was $>60 \%$. Even after adjustment for history of CAD, DWS was significantly associated with HF symptoms in the moderate AS patients (odds ratio 0.94, 95\% confidence interval [CI] 0.92-0.96; $P<.001$ ).

Furthermore, in the moderate AS patients, in those without CAD, DWS was clearly lower in the patients with than without $\mathrm{HF}(0.23 \pm 0.07$ vs $0.26 \pm 0.07 ; P<.05)$. Therefore, although we can not exclude the influence of CAD, the association between increased LV myocardial and chamber stiffness and HF appears to be independent from this factor. Third, there is no invasive measurement of diastolic stiffness to compare these measures. In the present study, however, several parameters, including increased $\mathrm{E} / \mathrm{e}^{\prime}$ and LA volume index, indicate increased filling pressures in patients with HF which also indirectly suggest increased LV chamber stiffness. Fourth, several studies have shown the validity of DWS for assessing diastolic LV stiffness, ${ }^{6,28,29}$ but there is some uncertainty regarding its reliability to reflect LV myocardial stiffness. In the HyperGEN cohort, DWS was closely associated with systolic strain parameters and early diastolic tissue velocities but not LV chamber stiffness. ${ }^{30}$ Although LV chamber stiffness is not necessarily equal to LV myocardial stiffness, they should be closely associated with each other. Also, the equation of DWS can be converted from DWS $=(\mathrm{PWs}-\mathrm{PWd}) / \mathrm{PWs}$ to DWS $=1-\mathrm{PWd} / \mathrm{PWs}$. $\mathrm{PWd} / \mathrm{PWs}$ is the reciprocal of the indicator of wall thickening; thus, the equation of DWS contains a systolic function parameter. However, in the present study, $\mathrm{K}_{\mathrm{LV}}$ was evaluated as well as DWS, and the results were similar. DWS was negatively correlated with $\mathrm{K}_{\mathrm{LV}}$ after adjustment for age, sex, race, body mass index, and history of HTN, diabetes, and CAD (coefficient $-0.313,95 \% \mathrm{CI}$ -0.496 to $-0.129 ; P=.001)$. Therefore, DWS may well reflect LV chamber stiffness in this study. Fifth, DWS incorporates changes in wall thickness in the early-diastolic phase that are affected by both LV relaxation and stiffness. However, an earlier study showed significant correlations between DWS and the myocardial stiffness constant, which is the criterion standard of the measurement of LV myocardial stiffness. ${ }^{6}$ Therefore, we think that DWS could be used as an indicator of LV myocardial stiffness in clinical settings. Finally, although DWS and $\mathrm{K}_{\mathrm{LV}}$ evaluated at resting state are associated with HFpEF, these findings 
do not necessarily suggest that they are the dominant mechanisms for exertional intolerance or dyspnea during exercise.

\section{Clinical Implications and Conclusion}

Whereas standard echocardiographic indices routinely used to assess AS severity were not associated with HF symptoms, we showed that novel echocardiographic indices of diastolic stiffness are independently associated with HF symptoms in patients with moderate to severe AS and preserved EF. This association was independent from diastolic function measures and LV filling parameters, including E/e', which have been associated with HF symptoms in earlier studies. Therefore, measurement of LV diastolic myocardial (DWS) and chamber $\left(\mathrm{K}_{\mathrm{LV}}\right)$ stiffness parameters may provide important incremental information about the condition of the LV myocardium and chamber conditions in moderate to severe AS patients.

\section{Supplementary Material}

Refer to Web version on PubMed Central for supplementary material.

\section{Acknowledgments}

Michael E. Hall is supported by grant number 1K08DK099415 from the National Institutes of Health.

\section{Appendix: Supplementary Data}

Supplementary data related to this article can be found at doi:10.1016/j.cardfail.

2017.05.002.

\section{References}

1. Osnabrugge RL, Mylotte D, Head SJ, Van Mieghem NM, Nkomo VT, LeReun CM, et al. Aortic stenosis in the elderly: disease prevalence and number of candidates for transcatheter aortic valve replacement: a meta-analysis and modeling study. J Am Coll Cardiol. 2013; 62:1002-12. [PubMed: 23727214]

2. Horstkotte D, Loogen F. The natural history of aortic valve stenosis. Eur Heart J. 1988; 9(SupplE): 57-64.

3. Vahanian A, Baumgartner H, Bax J, Butchart E, Dion R, Filippatos G, et al. Guidelines on the management of valvular heart disease: the Task Force on the Management of Valvular Heart Disease of the European Society of Cardiology. Eur Heart J. 2007; 28:230-68. [PubMed: 17259184]

4. Zile MR, Baicu CF, Ikonomidis JS, Stroud RE, Nietert PJ, Bradshaw AD, et al. Myocardial stiffness in patients with heart failure and a preserved ejection fraction: contributions of collagen and titin. Circulation. 2015; 131:1247-59. [PubMed: 25637629]

5. Takeda Y, Sakata Y, Mano T, Ohtani T, Kamimura D, Tamaki S, et al. Competing risks of heart failure with preserved ejection fraction in diabetic patients. Eur J Heart Fail. 2011; 13:664-9. [PubMed: 21415098]

6. Takeda Y, Sakata Y, Higashimori M, Mano T, Nishio M, Ohtani T, et al. Noninvasive assessment of wall distensibility with the evaluation of diastolic epicardial movement. J Card Fail. 2009; 15:6877. [PubMed: 19181296]

7. Marino P, Little WC, Rossi A, Barbieri E, Anselmi M, Destro G, et al. Can left ventricular diastolic stiffness be measured noninvasively? J Am Soc Echocardiogr. 2002; 15:935-43. [PubMed: 12221410] 
8. Baumgartner H, Hung J, Bermejo J, Chambers JB, Evangelista A, Griffin BP, et al. Echocardiographic assessment of valve stenosis: EAE/ASE recommendations for clinical practice. J Am Soc Echocardiogr. 2009; 22:1-23. quiz 101-102. [PubMed: 19130998]

9. McKee PA, Castelli WP, McNamara PM, Kannel WB. The natural history of congestive heart failure: the Framingham study. N Engl J Med. 1971; 285:1441-6. [PubMed: 5122894]

10. Lang RM, Badano LP, Mor-Avi V, Afilalo J, Armstrong A, Ernande L, et al. Recommendations for cardiac chamber quantification by echocardiography in adults: an update from the American Society of Echocardiography and the European Association of Cardiovascular Imaging. J Am Soc Echocardiogr. 2015; 28:1-39, e14. [PubMed: 25559473]

11. King DL, El-Khoury Coffin L, Maurer MS. Myocardial contraction fraction: a volumetric index of myocardial shortening by freehand three-dimensional echocardiography. J Am Coll Cardiol. 2002; 40:325-9. [PubMed: 12106939]

12. Sohn DW, Chai IH, Lee DJ, Kim HC, Kim HS, Oh BH, et al. Assessment of mitral annulus velocity by Doppler tissue imaging in the evaluation of left ventricular diastolic function. $\mathrm{J}$ Am Coll Cardiol. 1997; 30:474-80. [PubMed: 9247521]

13. Nagueh SF, Appleton CP, Gillebert TC, Marino PN, Oh JK, Smiseth OA, et al. Recommendations for the evaluation of left ventricular diastolic function by echocardiography. J Am Soc Echocardiogr. 2009; 22:107-33. [PubMed: 19187853]

14. Hachicha Z, Dumesnil JG, Bogaty P, Pibarot P. Paradoxical low-flow, low-gradient severe aortic stenosis despite preserved ejection fraction is associated with higher afterload and reduced survival. Circulation. 2007; 115:2856-64. [PubMed: 17533183]

15. Garcia D, Dumesnil JG, Durand LG, Kadem L, Pibarot P. Discrepancies between catheter and Doppler estimates of valve effective orifice area can be predicted from the pressure recovery phenomenon: practical implications with regard to quantification of aortic stenosis severity. $\mathrm{J} \mathrm{Am}$ Coll Cardiol. 2003; 41:435-42. [PubMed: 12575972]

16. Dahl JS, Christensen NL, Videbaek L, Poulsen MK, Carter-Storch R, Hey TM, et al. Left ventricular diastolic function is associated with symptom status in severe aortic valve stenosis. Circ Cardiovasc Imaging. 2014; 7:142-8. [PubMed: 24173271]

17. Park SJ, Enriquez-Sarano M, Chang SA, Choi JO, Lee SC, Park SW, et al. Hemodynamic patterns for symptomatic presentations of severe aortic stenosis. JACC Cardiovasc Imaging. 2013; 6:13746. [PubMed: 23489526]

18. Carabello BA. The symptoms of aortic stenosis: a step closer to understanding their cause. JACC Cardiovasc Imaging. 2013; 6:147-9. [PubMed: 23489527]

19. Little WC, Ohno M, Kitzman DW, Thomas JD, Cheng CP. Determination of left ventricular chamber stiffness from the time for deceleration of early left ventricular filling. Circulation. 1995; 92:1933-9. [PubMed: 7671378]

20. Monrad ES, Hess OM, Murakami T, Nonogi H, Corin WJ, Krayenbuehl HP. Abnormal exercise hemodynamics in patients with normal systolic function late after aortic valve replacement. Circulation. 1988; 77:613-24. [PubMed: 3342492]

21. Gjertsson P, Caidahl K, Farasati M, Oden A, Bech-Hanssen O. Preoperative moderate to severe diastolic dysfunction: a novel Doppler echocardiographic long-term prognostic factor in patients with severe aortic stenosis. J Thorac Cardiovasc Surg. 2005; 129:890-6. [PubMed: 15821660]

22. Kafa R, Kusunose K, Goodman AL, Svensson LG, Sabik JF, Griffin BP, et al. Association of abnormal postoperative left ventricular global longitudinal strain with outcomes in severe aortic stenosis following aortic valve replacement. JAMA Cardiol. 2016; 1:494-6. [PubMed: 27438331]

23. Carstensen HG, Larsen LH, Hassager C, Kofoed KF, Dalsgaard M, Kristensen CB, et al. Tissue velocities and myocardial deformation in asymptomatic and symptomatic aortic stenosis. J Am Soc Echocardiogr. 2015; 28:969-80. [PubMed: 25944424]

24. Briand M, Dumesnil JG, Kadem L, Tongue AG, Rieu R, Garcia D, et al. Reduced systemic arterial compliance impacts significantly on left ventricular afterload and function in aortic stenosis: implications for diagnosis and treatment. J Am Coll Cardiol. 2005; 46:291-8. [PubMed: 16022957]

25. Kruszelnicka O, Chmiela M, Bobrowska B, Swierszcz J, Bhagavatula S, Bednarek J, et al. Depressed systemic arterial compliance is associated with the severity of heart failure symptoms in 
moderate-to-severe aortic stenosis: a cross-sectional retrospective study. Int J Med Sci. 2015; 12:552-8. [PubMed: 26180511]

26. Harada K, Saitoh T, Tanaka J, Shibayama K, Berdejo J, Shiota T. Valvuloarterial impedance, but not aortic stenosis severity, predicts syncope in patients with aortic stenosis. Circ Cardiovasc Imaging. 2013; 6:1024-31. [PubMed: 24036387]

27. Bahlmann E, Gerdts E, Cramariuc D, Gohlke-Baerwolf C, Nienaber CA, Wachtell K, et al. Prognostic value of energy loss index in asymptomatic aortic stenosis. Circulation. 2013; 127:1149-56. [PubMed: 23357717]

28. Ohtani T, Mohammed SF, Yamamoto K, Dunlay SM, Weston SA, Sakata Y, et al. Diastolic stiffness as assessed by diastolic wall strain is associated with adverse remodelling and poor outcomes in heart failure with preserved ejection fraction. Eur Heart J. 2012; 33:1742-9. [PubMed: 22645191]

29. Liu YW, Lee WH, Lin CC, Huang YY, Lee WT, Lee CH, et al. Left ventricular diastolic wall strain and myocardial fibrosis in treated hypertension. Int J Cardiol. 2014; 172:e304-6. [PubMed: 24461969]

30. Selvaraj S, Aguilar FG, Martinez EE, Beussink L, Kim KY, Peng J, et al. Diastolic wall strain: a simple marker of abnormal cardiac mechanics. Cardiovasc Ultrasound. 2014; 12:40. [PubMed: 25277882] 

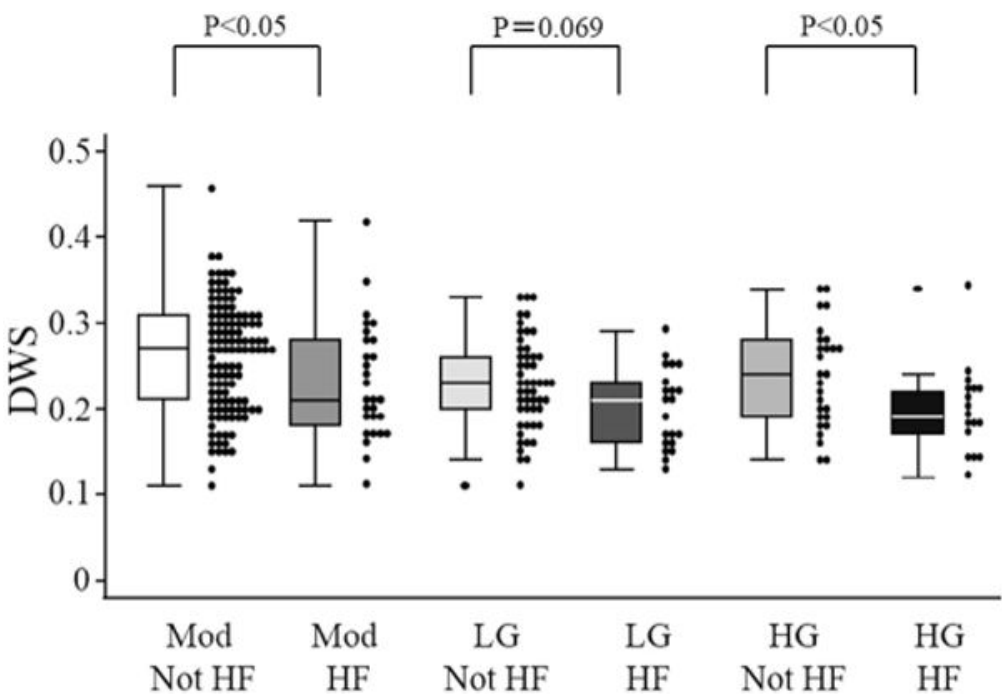

Fig. 1.

Diastolic wall strain (DWS) in each aortic stenosis (AS) severity category. In high-gradient sever (HG) AS and moderate (Mod) AS, the patients with heart failure (HF) symptoms had lower values of DWS than those without HF symptoms. In low-gradient severe (LG) AS, the patients with HF symptoms tended to have lower DWS than those without HF symptoms, but not statistically significantly. The whiskers on the box plots indicate interquartile ranges. The plots on the right side of the box plots represent individual data. 


\section{Table 1}

Baseline Characteristics of the Study Patients Stratified by Heart Failure (HF) Status

\begin{tabular}{|c|c|c|c|}
\hline Variable & $\begin{array}{l}\text { AS HF (-) } \\
(n=206)\end{array}$ & $\begin{array}{l}\operatorname{AS} \text { HF }(+) \\
(n=69)\end{array}$ & $P$ Value \\
\hline Age, y & $70 \pm 13$ & $75 \pm 13$ & .018 \\
\hline Male sex, $\%$ & $47 \%$ & $35 \%$ & .087 \\
\hline Body mass index, $\mathrm{kg} / \mathrm{m}^{2}$ & $30 \pm 7$ & $32 \pm 9$ & .017 \\
\hline Systolic BP, mm Hg & $139 \pm 23$ & $142 \pm 25$ & .345 \\
\hline Diastolic BP, mm Hg & $72 \pm 15$ & $68 \pm 14$ & .084 \\
\hline Heart rate, beats/min & $71 \pm 15$ & $74 \pm 17$ & .157 \\
\hline Hypertension & $83 \%$ & $96 \%$ & .009 \\
\hline Diabetes & $38 \%$ & $49 \%$ & .098 \\
\hline Dyslipidemia & $46 \%$ & $37 \%$ & .213 \\
\hline Coronary artery disease & $26 \%$ & $42 \%$ & .010 \\
\hline Current smoker & $18 \%$ & $14 \%$ & .501 \\
\hline African-American race & $33 \%$ & $49 \%$ & .012 \\
\hline Beta-blocker & $36 \%$ & $56 \%$ & .005 \\
\hline Calcium channel blocker & $34 \%$ & $38 \%$ & .565 \\
\hline ACEI or ARB & $48 \%$ & $50 \%$ & .799 \\
\hline Diuretics & $36 \%$ & $69 \%$ & $<.001$ \\
\hline Spironolactone & $6 \%$ & $7 \%$ & .729 \\
\hline Lipid-lowering agents, $\%$ & $51 \%$ & $56 \%$ & .467 \\
\hline NYHA II & & $36(52 \%)$ & N/A \\
\hline NYHA III or IV & & $33(48 \%)$ & N/A \\
\hline HG AS & $33(16 \%)$ & $18(26 \%)$ & .170 \\
\hline LG AS & $54(26 \%)$ & $17(25 \%)$ & \\
\hline Mod AS & $119(58 \%)$ & $34(49 \%)$ & \\
\hline
\end{tabular}

Results are presented as mean $\pm \mathrm{SE}, \%$, or $\mathrm{n}(\%)$. ACEI, angiotensin-converting enzyme inhibitor; ARB, angiotensin receptor blocker; AS, aortic stenosis; BP, blood pressure; HG, high-gradient severe; LG, low-gradient severe; Mod, moderate; NYHA, New York Heart Association function class. 
Table 2

Echocardiographic and Hemodynamic Data of the Study Patients Stratified by HF Status

\begin{tabular}{|c|c|c|c|}
\hline Variable & $\begin{array}{l}\text { AS HF (-) } \\
(n=206)\end{array}$ & $\begin{array}{l}\text { AS HF (+) } \\
(n=69)\end{array}$ & $P$ Value \\
\hline LV diastolic dimension, $\mathrm{mm}$ & $42.4 \pm 6.2$ & $43.7 \pm 6.4$ & .121 \\
\hline LV systolic dimension, $\mathrm{mm}$ & $25.9 \pm 5.1$ & $27.7 \pm 5.2$ & .010 \\
\hline Stroke volume, $\mathrm{mL}$ & $76.8 \pm 23.5$ & $78.4 \pm 24.7$ & .623 \\
\hline Stroke volume index, $\mathrm{mL} / \mathrm{m}^{2}$ & $39.5 \pm 11.5$ & $40.5 \pm 12.6$ & .547 \\
\hline LVEF, \% & $63.6 \pm 8.2$ & $60.7 \pm 7.3$ & .008 \\
\hline MCF, \% & $38.7 \pm 10.9$ & $33.6 \pm 8.6$ & $<.001$ \\
\hline LVMI, $\mathrm{g} / \mathrm{m}^{2}$ & $112 \pm 32$ & $131 \pm 41$ & $<.001$ \\
\hline Relative wall thickness & $0.65 \pm 0.16$ & $0.68 \pm 0.18$ & .249 \\
\hline E-wave velocity, $\mathrm{cm} / \mathrm{s}$ & $97 \pm 26$ & $117 \pm 28$ & $<.001$ \\
\hline A-wave velocity, $\mathrm{cm} / \mathrm{s}$ & $103 \pm 28$ & $105 \pm 34$ & .761 \\
\hline $\mathrm{E} / \mathrm{A}$ & $1.00 \pm 0.43$ & $1.24 \pm 0.56$ & .001 \\
\hline Deceleration time, ms & $240 \pm 69$ & $223 \pm 76$ & .099 \\
\hline $\mathrm{e}^{\prime}, \mathrm{cm} / \mathrm{s}$ & $5.92 \pm 1.82$ & $5.97 \pm 2.49$ & .877 \\
\hline $\mathrm{E} / \mathrm{e}^{\prime}$ & $17.4 \pm 6.9$ & $22.8 \pm 10.3$ & $<.001$ \\
\hline DWS & $0.25 \pm 0.06$ & $0.21 \pm 0.06$ & $<.001$ \\
\hline $\mathrm{K}_{\mathrm{LV}}$ & $0.13 \pm 0.08$ & $0.17 \pm 0.11$ & .004 \\
\hline LA volume index, $\mathrm{mL} / \mathrm{m}^{2}$ & $31.0 \pm 14.2$ & $37.3 \pm 13.8$ & .002 \\
\hline Estimated RVSP, mm Hg & $38.5 \pm 12.1$ & $46.2 \pm 12.4$ & $<.001$ \\
\hline Peak PG, mm Hg & $46.2 \pm 26.8$ & $48.6 \pm 33.0$ & .543 \\
\hline Mean PG, mm Hg & $25.6 \pm 15.7$ & $27.7 \pm 20.1$ & .382 \\
\hline AVA, $\mathrm{cm}^{2}$ & $1.05 \pm 0.29$ & $0.99 \pm 0.33$ & .164 \\
\hline AVAI, $\mathrm{cm}^{2} / \mathrm{m}^{2}$ & $0.55 \pm 0.17$ & $0.51 \pm 0.17$ & .129 \\
\hline Dimensionless index & $0.35 \pm 0.11$ & $0.32 \pm 0.12$ & .122 \\
\hline 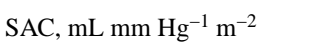 & $0.59 \pm 0.22$ & $0.51 \pm 0.22$ & .012 \\
\hline $\mathrm{Zva}, \mathrm{mm} \mathrm{Hg} \mathrm{mL} L^{-1} \mathrm{~m}^{-2}$ & $4.82 \pm 1.52$ & $5.14 \pm 1.29$ & .134 \\
\hline Energy loss index, $\mathrm{cm}^{2} \mathrm{~m}^{-2}$ & $1.05 \pm 0.29$ & $1.01 \pm 0.31$ & .367 \\
\hline
\end{tabular}

AVA, aortic valve area; AVAI, aortic valve area index; DWS, diastolic wall strain; $\mathrm{e}^{\prime}$, peak early diastolic mitral annulus movement; LA, left atrial; LV, left ventricular; LVEF, left ventricular ejection fraction; LVMI, left ventricular mass index; MCF, myocardial contraction fraction; PG, pressure gradient; RVSP, right ventricular systolic pressure; SAC, systemic arterial compliance; Zva, valvulo-arterial impedance; other abbreviations as in Table 1. 
Table 3

Univariable Logistic Regression Analysis of Determinants of HF Status

\begin{tabular}{lccc}
\hline Variable & OR & 95\% CI & P Value \\
\hline Age (per 1 y increase) & 1.02 & $1.00-1.05$ & .019 \\
Male sex & 0.61 & $0.35-1.08$ & .088 \\
African-American race (vs the other races) & 2.02 & $1.16-3.51$ & .013 \\
Body mass index (per 1-unit increase) & 1.04 & $1.01-1.08$ & .019 \\
Systolic BP (per 1 mm Hg increase) & 1.01 & $0.99-1.02$ & .344 \\
Diastolic BP (per 1 mm Hg increase) & 0.98 & $0.96-1.00$ & .085 \\
Heart rate (per 1 beat/min increase) & 1.01 & $1.00-1.03$ & .158 \\
Hypertension & 4.43 & $1.31-14.9$ & .016 \\
Diabetes & 1.59 & $0.92-2.76$ & .099 \\
Dyslipidemia & 0.70 & $0.40-1.23$ & .214 \\
Coronary artery disease & 2.11 & $1.19-3.73$ & .011 \\
Current smoker & 0.77 & $0.36-1.66$ & .501 \\
Peak PG (per 1 mm Hg increase) & 1.00 & $0.99-1.01$ & .542 \\
Mean PG (per 1 mm Hg increase) & 1.01 & $0.99-1.02$ & .382 \\
AVAI (per 1 cm²/m increase) & 0.28 & $0.06-1.44$ & .129 \\
Dimensionless index (per 1 unit increase) & 0.14 & $0.01-1.72$ & .123 \\
LV mass index (per 1 g/m ${ }^{2}$ increase) & 1.02 & $1.01-1.02$ & $<.001$ \\
LVEF (per 1 \% increase) & 0.95 & $0.92-0.99$ & .009 \\
Myocardial contraction fraction & 0.95 & $0.92-0.98$ & .001 \\
(per 1 \% increase) & & & \\
E/e' (per 1 unit increase) & 1.07 & $1.04-1.12$ & $<.001$ \\
DWS (per 0.01 unit increase) & 0.90 & $0.86-0.95$ & $<.001$ \\
$\mathrm{~K}_{\mathrm{LV}}$ (per 0.01 unit increase) & 1.04 & $1.01-1.07$ & .005 \\
SAC (per 0.01 unit increase) & 0.98 & $0.97-1.00$ & .014 \\
Zva (per 1 unit increase) & 1.15 & $0.96-1.39$ & .135 \\
Energy loss index (per 1 unit increase) & 0.64 & $0.24-1.68$ & .366 \\
\hline & & & \\
\hline
\end{tabular}

CI, confidence interval; OR, odds ratio; other abbreviations as in Table 1 and 2. 


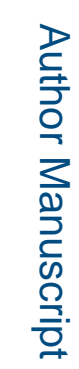

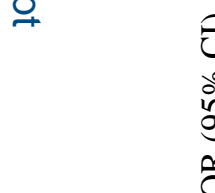

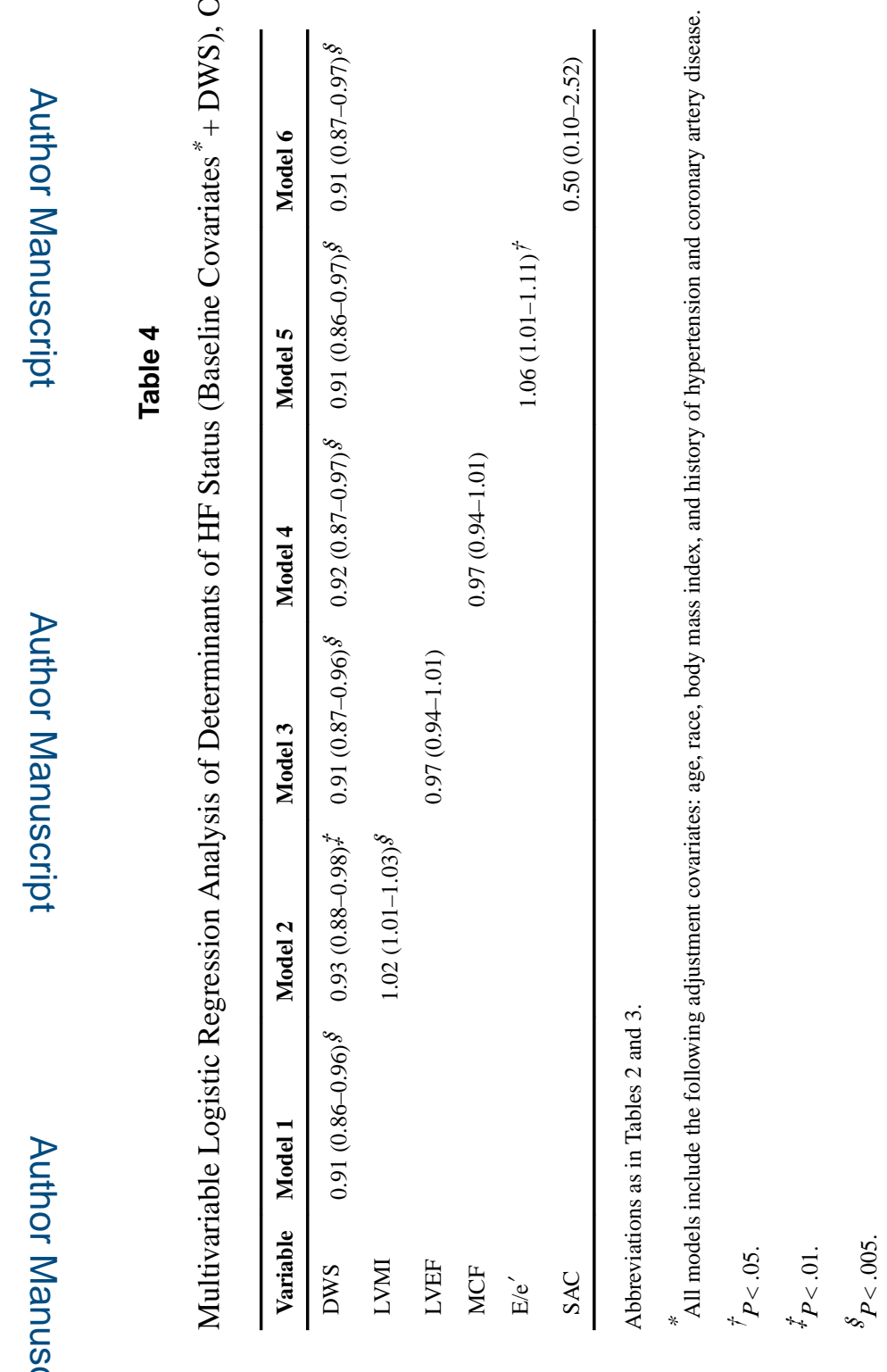

J Card Fail. Author manuscript; available in PMC 2018 August 20. 


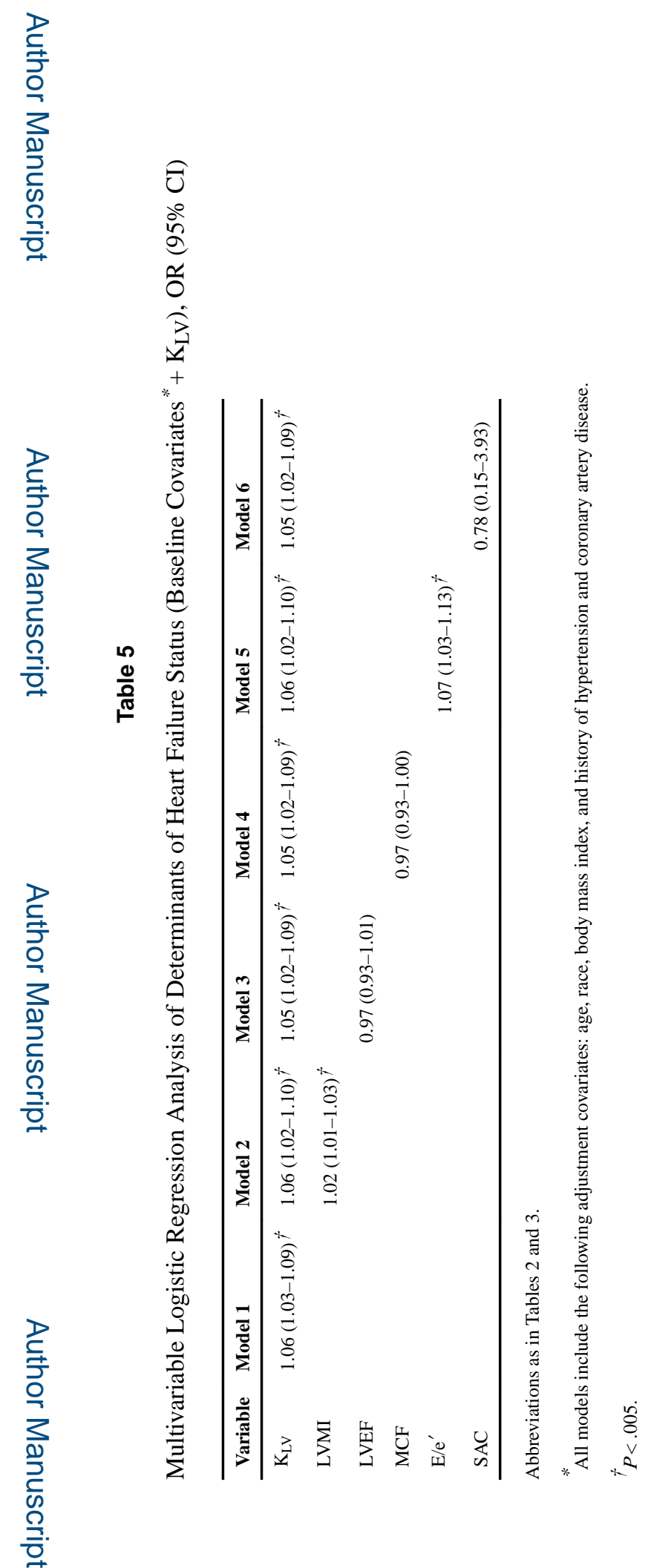

J Card Fail. Author manuscript; available in PMC 2018 August 20. 